\title{
A study of adverse events in an intensive care unit in Morocco
}

\section{Hicham Bakkali*, Salahedine Massou, Mohamed Moutaoukil, Khalil Aboulaala, Hicham Balkhi, Charqui Haimeur}

Department of Anesthesiology and Critical Care, Military Training Hospital Med V, Rabat, Morocco; Faculty of Medicine and Pharmacy, University Med V, Rabat, Morocco

\section{Email address:}

hbakkali@ymail.com (H. Bakkali), salah_masson80@hotmail.com (S. Massou), khalil_akram98@yahoo.fr (K. Aboulaala), balkhih@hotmail.com (H. Balkhi), drhaimeur@hotmail.com (C. Haimeur)

\section{To cite this article:}

Hicham Bakkali, Salahedine Massou, Mohamed Moutaoukil, Khalil Aboulaala, Hicham Balkhi, Charqui Haimeur. A Study of Adverse Events in an Intensive Care Unit in Morocco. American Journal of Nursing Science. Vol. 3, No. 6, 2014, pp. 100-104.

doi: 10.11648/j.ajns.20140306.12

\begin{abstract}
Adverse events in an intensive care unit can raise important medical, ethical, legal and economic problems. This study aims at pointing out these adverse events, by assessing their severity, identifying the very risk factors associated with them, and comparing our results with existing evidence-based data. Material and methods: This is a retrospective study in the intensive care unit of the Military Hospital of Instruction Mohammed V, at RABAT, carried out over a period of 3 years and half. Included in the study are medical records of patients with an adverse event (AE) during their hospitalization in the IC (Intensive Care) or elsewhere, and who required a stay in Intensive care. We excluded nosocomial infections and adverse events due to medicated side effects, as there is no conclusive evidence of the accountability of the event to the product. Results: The study focuses on 813 patients. 44 patients experienced at least one adverse event, with an incidence of $5.4 \%$. They were dominated by those of respiratory type (34\%), followed by cardiovascular events and neurological disorders. All events were considered as preventable. The identified risk factors were due to human errors in $95 \%$ of cases: mainly, careless mistakes. The consequences of adverse events were of varying severity, with a mortality rate of $39 \%$ and a residence time of 12 days on average, comparable to those of other patients without iatrogenic complications. Conclusion: In our study, AE are dominated by events of respiratory type, and human error is the main associated factor. The specific impact of these events on prognosis is difficult to assess because they occur in serious situations. The monitoring of AE may constitute a care quality indicator.
\end{abstract}

Keywords: Adverse Event, Risk Factor, Severity, Iatrogenic

\section{Introduction}

The scope of our company to iatrogenic risk increases with the health system effectiveness. Control or manage risk in this context means avoid and detect adverse events which can be preventable and whose impact for the patient can be limited [1]. Frequency and severity of iatrogenic risks vary from one specialty to another and are more important when the patient require extensive and invasive treatments $[2,3]$. It is the case of intensive care where iatrogenic pathology is a major concern. It is favored by several factors including the selection of severely ill patients and the use of invasive techniques of investigation and care $[2,4]$. At a time when the assessment in intensive care has become a regular and rational practice, the statement could be, with the classic severity score, an important marker of care quality. Our work was aimed at studying the incidence of AE in ICU, their types and the main factors associated with them.

\section{Materials and Methods}

It is a retrospective study achieved in versatile ICU of Rabat Mohamed $\mathrm{V}$ training military hospital over a period of 3 years and half. This service includes Intensive medical care unit and an intensive surgical care unit. Each one has the capacity of 12 beds divided into 12 separate rooms. The unit operates alternatively and the unit, as a function, admits patients of versatile intensive care. The medical team is composed of 4 
intensivists physicians, two resident doctors of anesthesia-resuscitation and one internist. Care is provided $24 \mathrm{~h} / 24 \mathrm{~h}$ by one resident or one internist and by one specialist. Paramedical team is composed of 1nursing staff, 2 medical secretaries, 16 nurses, three aides and three laborers. On average, 4 nurses work during the day and 4 during the night in the rate of one day to two. The nurse/patient ratio is about 1 to 2 . Were included, patients with adverse events during their hospitalization in Intensive care unit or elsewhere, or required a stay in intensive care unit. Patients with AE of infectious type, those with decubitus complication and those with $\mathrm{AE}$ due to medicated side effects in the absence of no conclusive evidence of the accountability of the event to the product were excluded from this study. Quantitative variables are expressed as mean $+/$ - standard deviation and compared by $<$ Student's $t>$ test. Qualitative variables are expressed as percentage and compared by Chi 2 test. The risk of first kind is chosen arbitrarily to $5 \%$ and therefore, any value of $p<0.05$ was considered statistically significant.

\section{Results}

During the study period, 813 patients were admitted into the versatile Intensive care of military training hospital Mohamed $\mathrm{V}$ in Rabat. 44 patients were admitted for $\mathrm{AE}$ or did presented one during their hospitalization. Average age of those patients with AE was $46,5 \pm 15$ years, with extremes of 18 and 72 years. Among those 44 patients, were 28 men (64\%) and 16 women (36\%) with sex-ratio $\mathrm{M} / \mathrm{F}$ of 1,75 . The assessment of the severity of the condition of the patients was based on the calculation of severity scores during the first 24 hours. IGS $\mathrm{II}=28 \pm 16$ on average, with extremes of 5 and 78 . APACHE II= $18,5 \pm 9$ on average, with extremes of 4 and 36 . Severity score ISS, calculated for 4 patients admitted for serious trauma, has been on average $32 \pm 14$, with extremes of 8 to 50. Among those 44 patients, $59 \%$ were admitted in Intensive care unit for one occurrence of commotif admission $\mathrm{AE}$ and $41 \%$ presented one $\mathrm{AE}$ in our service. Furthermore, there have been more surgical patients than medical ones $(66 \%)$, (Table 1$)$.

Table 1. Study population characteristics

\begin{tabular}{ll}
\hline Characteristics & n (\%) \\
\hline Patients & 44 \\
Sex-ratio (M/F) & $1,75(28 / 16)$ \\
Severity scores & \\
IGS II & $28 \pm 12$ \\
APACHE II & $18,5 \pm 9$ \\
Origin department & \\
Medical & $15(34 \%)$ \\
Surgical & $29(66 \%)$ \\
Causes of admissions & \\
Post operative & $19(43 \%)$ \\
Coma & $13(29,5 \%)$ \\
Respiratory failure & $6(14 \%)$ \\
Shock & $2(4,5 \%)$ \\
Trauma & $4(9 \%)$ \\
Period of hospitalization (days) & $12 \pm 5$ \\
\hline
\end{tabular}

Respiratory events were at the first position (34\%) and just behind, cardio vascular events followed (25\%), (Table2). AE occurred in our patients have been considered as preventable in $95 \%$ of cases. This inevitable or unavoidable nature could not be determined in 2 cases (5\%). Human error has been implicated in the almost totality of cases (95\%). It was careless mistake (67\%), knowledge mistake (19\%) and human error associated with a policy violation (14\%). In 6 cases (14\%), only human error has been described as a cause of AE occurrence. Human error related to equipment and / or diagnostic and therapeutic procedures have occurred in patients $(82 \%)$. No precision of this human error was reported in 2 cases (4\%). Medical staff has been incriminated in $89 \%$ of cases, specialist in $57 \%$, resident in $25 \%$, and internist in $7 \%$ against $11 \%$ for paramedical staff.

Table 2. Various types of adverse events

\begin{tabular}{ll}
\hline Adverse events & $\mathbf{n}(\mathbf{\%})$ \\
\hline Respiratory & $15(34 \%)$ \\
Pneumothorax & 6 \\
Extubation & 4 \\
Inhalation pneumonia & 3 \\
Hemothorax & 1 \\
Cervical compressive hematoma & 1 \\
Cardiovascular & $11(25 \%)$ \\
Hemorrhage/ vascular wound & 7 \\
Cardiac arrest & 2 \\
Cardiogenic shock & 1 \\
Pulmonary embolism & 1 \\
Neurological & $10(23 \%)$ \\
Intracranial hypertension syndrome & 5 \\
Postoperative stroke & 2 \\
Cerebral hematoma & 1 \\
Cerebral contusion & 1 \\
Postoperative coma & 1 \\
Uro-Nephrology & $2(4,5 \%)$ \\
Incomplete dialysis & 1 \\
Bladder rupture & 1 \\
Ophthalmological & $2(4,5 \%)$ \\
Corneal ulcer & 1 \\
Bilateral keratitis & 1 \\
Others & 1 \\
Wound of the colon & 1 \\
Extravasation of the central venous line & 1 \\
Ignored fracture of the cervical spine & \\
Dental fracture & \\
\hline &
\end{tabular}

No consequence has been established concerning $\mathrm{AE}$ occurrence in one case $(2 \%)$.Were reported events of moderate severity, requiring a local treatment of short duration in $20 \%$ of cases. A statement of severe consequence, having required a non-invasive general treatment in $25 \%$ of cases was provided. One severe consequence requiring one general and/or invasive treatment in $14 \%$ of cases was observed. Mortality rate in our series was of $39 \%$ against one of $33 \%$ in all admitted patients during the same period. The hospitalization of patients with $\mathrm{AE}$ was $12 \pm 5$ days with extremes of 1 and 74 days.

Gender and surgical admission reason, was not significant for $\mathrm{AE}$ occurrence. However, the one of medical admission was significant statistic factor $(p=0,0025)$. Neither age, nor length of stay or severity scores have been significant factors 
occurrence of $\mathrm{AE}$ between the two groups of patients.

\section{Discussion}

The incidence of AE in ICU is varying between $3 \%$ and $37,5 \%$ and seems to depend on definitions criteria, study retrospective or prospective character. It depends also on specificity of hospital services where they happened $[2,4,5$, $6]$. In our study, the incidence was of $5,4 \%$. However, it remains important because of the threatening or fatal consequences that these $\mathrm{AE}$ may bring out. Infectious, respiratory and cardio-vascular complications $[7,8]$ are at the first position of observed AE. In our study, we have excluded the AE of infectious type. Our results are closed to those of literature and were dominated by respiratory AE type. After them, those of neurological type and cardio-vascular type are following.

The influence of age in AE occurrence is questionable. Age is considered as a predisposing factor in some studies $[9,10]$ unlike others [7]. In our study, the average age of patients unaffected by $\mathrm{AE}(49 \pm 17$ years), is discreetly higher than the one of our 44 patients. This reflects the youth of our population compared to the rest of the patients admitted in ICU during the same period. However, we take shared findings with some studies though very likely. The influence of age on frequency of $\mathrm{AE}$ is difficult to determine being given the involvement of advanced age, due to many factors favoring and related to the situation of the acute affection.

Gender influence on the incidence of AE in the ICU remains to prove. In literature, sex-ratio is very low [7, 9] in opposition to our study where sex-ratio is 1,75 with a male predominance. Sex-ratio $\mathrm{M} / \mathrm{F}$ in patients not victims of $\mathrm{AE}$ is 2,1 with always a male predominance. Moreover, among all patients admitted during study period $6,5 \%$ of female patients and $5,3 \%$ of male patients, have presented an AE. That means that female patients have more predispositions to be affected by $\mathrm{AE}$ event if the percentage of male patients affected by AE is higher. In Bouhaja et al [7] study, 72\% of patients affected by $\mathrm{AE}$ have been admitted for medical pathology, and $28 \%$ for surgery. In our study, surgical patients $(66 \%)$ were more numerous than medical ones (44\%). Darchy et study [9] was centered on iatrogenic pathology as a reason of ICU admission $18 \%$ were admitted for an AE after medical act and $22 \%$ after a surgery one. The severity of health condition while admitted at ICU, of patients victims of AE seems also important [7, 9]. IGS I estimated by Darchy et al was 13,4 on average and workload was 53 points Omega per patient. But in Bouhaja et al study, IGS II was 38,2 \pm 18 . MODS score 4,6 $\pm 3,5$ and index of total omega activity was $131,5 \pm 13,5$. These scores are higher in patients without AE and higher also in medical patients than in surgical ones.

We have established in our study 3 scores whose IGS II (average $28 \pm 12$ ) against $(25 \pm 14)$ to patients without AE. That means our patients were in better health condition while admitted than those of Tunisian study. But the score difference between patients without/with AE was not significant as in previous study. These 2 elements could in a certain way, explain the weaker AE incidence compared to Tunisian study. For that concern MODS and OMEGA scores, they were not considered in our study. The second score in our study was APACHE II, averaged slightly higher $(18,5 \pm 9)$ than in patients without AE (16 \pm 9$)$. Those same results were found in an American study with APACHE II score of 19, 9 in medical IC [11]. Finally, the third score in our study was ISS II averaged $32 \pm 14$, testifying enough serious state in which our patients, victims of serious trauma were admitted. In a general way, health condition fragility and severity of patients admitted in IC, has been considered as factor that favors occurrence of AE.

The human error was reported in almost totality of our patients $(95 \%)$. The position of human error in Bouhaja et al series is twice more important [7] than the one of Giraud and [2], respectively $60 \%$ and $32 \%$ in all AE. For major complications, human error was the cause of $\mathrm{AE}(77 \%)$ in the first series, comparatively to $39 \%$ in the other one [2]. In both studies, nurses made more errors than doctors. In our study, it was the medical staff that has been incriminated in $89 \%$ of AE against $11 \%$ for paramedical staff whereas Donchin et al study [8] revealed many human errors made by the doctors as well as the nurses. We must note that medical activity is planned with a great deal of errors due to acute distress situations with an important error risk. It was established a good correlation between medical and paramedical intensity activity and the human error incidence [2, 8]. In Bouhaja et al series, the relationship nurse/patient was $1 / 2,5$ to $1 / 3$ [2,13]. Although in our study like in the one of Donchin et al [8], the relationship nurse/patient was $1 / 2$, according to $\mathrm{NIH}$ recommendations [13], however, a precise evaluation of workload by Omega score was not calculated in our patients. Moreover, a workload considered as excessive and maximum by nurses was associated with major $\mathrm{AE}$ [2]. The analysis of human error during custody, 27 errors out 28errors attributed to the nurses, were due to lack of surveillance; whereas over 11 errors due to doctors, 6 were related to lack of experience [7]. The time when this error was made has not been determined in our series, but majority of AE happened during the night in Bouhaja et al study, but it was during the day for Donchin et al [8].

In our study, all AE happened in our patients were considered as preventable $(100 \%)$. In literature, preventable error rate varies between 28 and $84 \%$ according to the studies $[2,6,13,14,15]$. Nevertheless, it can partially explained by means of selection in ICU. Immediate causes of preventable $\mathrm{AE}$ were common $[2,16,17]$ : dosage error, contraindication or carelessness in interactions, lack of prophylaxis or surveillance and technique error.

In a French national investigation on AE related to cares [10] $40,5 \%$ of reported $\mathrm{AE}$ led only to an extension of hospitalization period whilst $8,5 \%$ of AEs have been associated with a decease and $36 \%$ have threatened the vital prognosis. Among these events, $40 \%$ have been considered as preventable. Taking in account the poor number of preventable events associated with no capacity or decease among observed cases, it is however, impossible to evaluate 
with precision the proportion of these cases among preventable AEs. In Darchy et al study [9], AE mortality in town was about $2-6 \%[18,19]$ and the one happened in the hospital at $4-14 \%[6,21]$. Occurrence of $\mathrm{AE}$ is threatening in $10-26 \%$ of cases [2, 16, 20, 21, 22]. That concerns the mortality of patients admitted in ICU for AE, it is not statistically different from the one of patients admitted for other reasons. In our study we have found higher rate of mortality among patients with $\mathrm{AE}(39 \%)$ against $33 \%$ in patients without AE. In deceased patients, occurrence has been held directly proportional responsible for death. In our study, the average hospitalization duration in patients with $\mathrm{AE}$ was of $12 \pm 5$ days against $10 \pm 5,5$ days in patients without AE. Statistically, the difference between the groups is not so significant. In Tunisian study, hospitalization duration in ICU in multivarious analyses, has been considered as one of the risk factor significantly associated with iatrogenic pathology [7]. Numbers found in that study are largely lower than in our study. Moreover, the difference of staying duration between the 2 groups is not significant in our series. In our study, we have not been able to evaluate, even approximately, extra cost causes generated by the occurrence of $\mathrm{AE}$ in a patient admitted in ICU. The financial consequences of $\mathrm{AE}$ are underestimated [9].

\section{Conclusion}

$\mathrm{AE}$ are frequent in ICU and are a non-negligent cause of deaths when they are medically supported. Securing medical care is now a priority. The improvements go start by consciousness raising that majority of care errors are not deliberate errors made by unintentional acts, but they are related to human errors. The real impact of AE on prognostics is difficult to appreciate as they happen first of all in serious cases. The health care practitioner's notion of risk management and the public safety and privacy concerns are of utmost priority for healthcare systems. A systematic and multidisciplinary collaboration and clear communication among doctors, nurses, biomedical engineers and administrators is vital to sustain healthcare institutions.

\section{References}

[1] Smith DG, Wheeler JRC. Strategies and structures for hospital risk management programs. Health Care Manage Rev. 1992; 17:9-17.

[2] Giraud T, Dhainaut JF, Vaxelaire JF, Joseph T, Journois D, Bleichner G, Sollet JP, Chevret S, Monsallier JF. Iatrogenic complications in adult intensive care units : a prospective two center study. Crit Care Med 1993; 21:40-51.

[3] Bloomfield Rubins H, Moskowitz MA. Complications of care in a medical intensive care unit. J Gen Intern Med 1990 ; $5: 104-9$.

[4] Trunet P, Lhoste F, Le Gall JR, Rapin M. Iatrogenic disease occurring in an ICU (article in french). Rean Soins Intens Med Urg 1987; 3:15-18.
[5] Steel K, Gertman PM, Crescenzic C, Anderson J. Iatrogenic illness on a general medical service at a university hospital. $\mathrm{N}$ Engl J Med $1981 ; 304: 638-42$

[6] Soufir L, Auroy Y. Field 2. Epidemiology (medical errors and patient adverse events). French-speaking society of intensive care. French society of anesthesia and resuscitation. Ann fr anesth rea 2008; 27: e59- 63 .

[7] Bouhaja B, Mermech M, Mestiri T, Ben Ayed M, Dhaouadi MZ, Ben Ammar M. Iatrogenic disease in the intensive care unit: a prospective study. Réanim Urgences 1999; 8: 319-26.

[8] Donchin Y, Gopher D, Olin M, Badihi Y, Biesky M, Sprung C L, Pizov R, Cotev S. A look into the nature and causes of human errors in the intensive care unit. Qual Saf Health Care $2003 ; 12: 143-148$.

[9] Darchy B, Le Mière E, Figueredo B, Bavoux E, Cadoux G, Domart Y. Patients admitted to the intensive care unit for iatrogenic disease. Risk factors and consequences. Rev Med Interne 1998; 19:470-8.

[10] Survey ENEIS 2004 - DREES. Serious adverse events related to treatment observed in health facilities: First results of a national study. Corrected version. (article in French). 398, May 2005.

[11] Rothschild JM, Landrigan CP, Cronin JW, Kaushal R, Lockley SW, Burdick E, Stone PH, Lilly CM, Katz JT, Czeisler CA, Bates DW.. The Critical Care Safety Study: The incidence and nature of adverse events and serious medical errors in intensive care. Crit Care Med 2005; 33: 1694-1700.

[12] Trunet P, Le Gall JR, Lhoste F, Regnier B, Saillard Y,Carlet J, Rapin M. The role of iatrogenic disease in admissions to intensive care. JAMA 1980; 244: 2617-20.

[13] Wilson RM, Runciman WB, Gibberd RW, Harrison BT,Newby L, Hamilton JD. The quality in Australian health care study. Med J Aust. 1995; 163: 458-71.

[14] Brennan TA, Leape LL, Laird NM, Hebert L, Localio AR, Lawthers AG, Newhouse JP, Weiler PC, Hiatt HH. Incidence of adverse events and negligence in hospitalized patients. Results of the Harvard Medical Practice study I. N Engl J Med 1991; 324:370-6.

[15] Brennan TA, Hebert LE, Laird NM, Lawthers A, Thorpe KE, Leape LL, Localio AR, Lipsitz SR, Newhouse JP, Weiler PC et al. Hospital characteristics associated with adverse events and substandard care JAMA. 1991; 265: 3265-9.

[16] Queneau P, Chabot JM, Rajaona H, Boissier C, Grandmottet P. Iatrogenic disease observed in a hospital setting. II. Analysis of causes and suggestions for novel preventive measures. Bull Acad Natl Med 1992; 176: 651-64.

[17] Leape LL, Brennan TA, Laird N, Lawthers AG, Localio AR, Barnes BA, Hebert L, Newhouse JP, Weiler PC, Hiatt H. The nature of adverse events in hospitalized patients. Results of yhe Harvard Medical Practice study II. N Engl J Med 1991; 324: 377-84.

[18] Hugues FC, Le Jeune C, Boutot F, Lowenstein W, Haas C. Evaluation of pathology of drug origin in a department of internal medicine. Ann Med Interne 1986; 137: 41-5.

[19] Roblot P, de Bayser L, Barrier J, Marechaud R, Becq-Giraudon B. Primum non nocere. Prospective study of 115 cases of iatrogenic diseases collected over one year in 106 patients. Rev Med Interne 1994; 15: 720-6. 
[20] Caranasos GJ, Stewart RB, Cluff LE. Drug-induced illness leading to hospitalization. JAMA 1974; 228: 713-7.

[21] Burnun JF. Preventability of adverse drug reactions. Ann Intern Med 1976; 85: 80-1.
[22] Burstin HR, Lipsitz SR, Brennan TA. Socioeconomic status and the risk for substandard medical care. JAMA 1992; 268: 2383-7. 